\title{
Análise comparativa em modelo computadorizado bidimensional com simulação do emprego de hastes flexíveis de aço e titânio, na fratura do fêmur da criança, utilizando o método dos elementos finitos*
}

\author{
Comparative analysis in a 2D computer model simulating \\ the use of steel and titanium elastic nails in pediatric \\ femur fracture, using the finite element method \\ Jamil Faissal Soni ${ }^{1}$, Cláudio Santili ${ }^{2}$, Carmen Lucia Penteado Lancellotti ${ }^{3}$, \\ Mildred Balin HeCKE ${ }^{4}$, Felipe ReCKA de Almeida ${ }^{5}$, LeANdro Zen KARAM ${ }^{6}$
}

\section{RESUMO}

Objetivo: Apresentar um modelo computadorizado bidimensional, simulando uma fratura do fêmur em criança tratada por hastes flexíveis de aço e titânio, utilizando o método dos elementos finitos, avaliando-se comparativamente o caminho e distribuição das tensões, tensões principais e deformações. Métodos: Foram utilizados dois modelos diferentes, gerados pelo aplicativo $A N S Y S^{\circledast}$, considerando a simulação de uma fratura transversal na região diafisária, com a espessura de 1mm, cuja estabilização foi feita mediante o emprego de hastes intramedulares de materiais diferentes (aço e titânio), à luz da teoria mecanostática proposta por Frost, em

* Trabalho Realizado na Faculdade de Ciências Médicas da Santa Casa de Misericórdia São Paulo - Programa de Pós-Graduação Doutorado - São Paulo, SP.

1. Professor Assistente de Ortopedia da Pontifícia Universidade Católica do Paraná - Curitiba (PR), Brasil.

2. Diretor do Departamento de Ortopedia "Pavilhão Fernandinho Simonsen" - Santa Casa de Misericórdia de São Paulo - São Paulo (SP), Brasil.

3. Professora Adjunto do Departamento de Ciências Patológicas da Santa Casa de Misericórdia de São Paulo - São Paulo (SP), Brasil.

Endereço para correspondência: Jamil Faissal Soni, Av. Silva Jardim, 1.502, apto. 91, Rebouças - 80250-200 - Curitiba, PR.

E-mail: jamilfsoni@ hotmail.com

Recebido em 6/11/07. Aprovado para publicação em 2/5/08.

Copyright RBO2008
1987. Resultados: A introdução das hastes intramedulares no fêmur alterou o caminho das tensões, servindo como condutoras das forças compressivas. Na análise comparativa, o modelo com as hastes de titânio, à luz da teoria mecanostática proposta por Frost, apresentou desempenho mais homogêneo quando do estudo das deformações em relação ao modelo com hastes de aço inoxidável. Conclusões: O modelo proposto atingiu os objetivos de comparar as tensões e deformações entre as simulações das hastes de aço e titânio. Analisando o caminho e distribuição das tensões no modelo (Von Mises e tensões principais), observa-se comportamento biome-

4. Professora Adjunto Departamento de Construção Civil - UFPRCuritiba (PR), Brasil.

5. Pós-graduando do Programa de Pós-Graduação em Métodos Numéricos em Engenharia da Universidade Federal do Paraná UFPR - Curitiba (PR), Brasil.

6. Pós-graduando do Centro ee Pós-Graduação em Engenharia Elétrica e Informática Industrial da Universidade Federal do Paraná - UFPR - Curitiba (PR), Brasil. 
cânico qualitativamente melhor no modelo com hastes de titânio; todavia, na análise quantitativa, restrita às regiões do foco de fratura, os valores são estatisticamente semelhantes. No estudo das deformações, observa-se comportamento biomecânico mais homogêneo no modelo com hastes de titânio, pois as deformações verificadas nas regiões do foco de fratura apresentam-se dentro das janelas fisiológicas propostas por Frost.

Descritores - Fixação intramedular de fraturas; Pinos ortopédicos; Análise de imagem assistida por computador; Análise de elemento finito; Estudo comparativo

\section{ABSTRACT}

Objective: To present a 2D computer model simulating a pediatric femur fracture treated with steel and titanium elastic nails, using the Finite Element Method, with a comparative evaluation of the paths and distribution of stresses, main stresses, and strains. Methods: Two different models were used, both generated by application ANSYS ${ }^{\circledR}$, considering the simulation of a $1 \mathrm{~mm}$ transversal fracture of the diaphysis whose stabilization was performed with the use of intramedullary nails made of different materials (steel and titanium), according to the Mechanostat Theory proposed by Frost in 1987. Results: The introduction of intramedullary nails in the femur has changed the path of stresses, and conducted compressive stresses. In the comparison, the model with titanium nails, according to the Mechanostat Theory proposed by Frost, presented a more homogenous performance in the strain study than the stainless steel nails. Conclusions: The model proposed attained the objective of comparing stresses and strains between the steel and titanium nails simulations. By analyzing the path and the distribution of stresses in the model (Von Mises and main stresses), one can see the qualitatively improved biomechanical behavior in the titanium nails model, but in the quantitative analysis restricted to the fracture focus regions, the values are statistically similar. In the strain study, the more homogenous biomechanical behavior is seen in the model with titanium nails, as all strains seen in fracture focus regions are within the physiological window proposed by Frost.

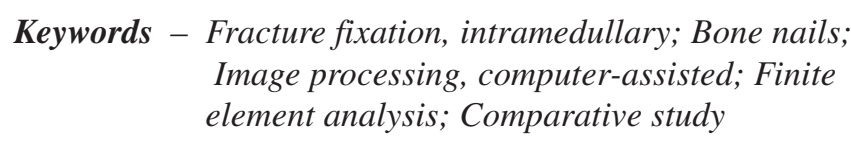

Keywords - Fracture fixation, intramedullary; Bone nails; Image processing, computer-assisted; Finite element analysis; Comparative study

\section{INTRODUÇÃO}

As hastes intramedulares flexíveis, sejam de aço inoxidável ou titânio, têm sido apontadas como excelente opção para o tratamento cirúrgico nas fraturas pediátricas há pelo menos 20 anos, por proporcionarem algumas vantagens: são inseridas através de pequenas incisões, poupam as placas de crescimento, utilizam instrumental simples e permitem carga precoce, devido à sua flexibilidade ${ }^{(1-2)}$.

Estudos sugerem que as hastes flexíveis intramedulares de titânio são o implante ideal para as fraturas femorais na população pediátrica, porém, ensaios biomecânicos são ainda escassos ${ }^{(3)}$. Torna-se fundamental o desenvolvimento de estudos de comportamento biomecânico desses implantes ortopédicos, podendo com isso colaborar para o melhor entendimento do processo de reparação da fratura, bem como correlacioná-los com os resultados clínicos favoráveis já demonstrados na literatura.

O método de elementos finitos (MEF) é uma ferramenta matemática utilizada para resolver problemas em Engenharia, sendo capaz de explorar os efeitos da aplicação de uma carga no osso e seu comportamento biomecânico. Uma de suas vantagens principais é poder ser utilizado em sólidos de geometria irregular que contenham propriedades materiais heterogêneas. $\mathrm{O} \mathrm{MEF}$ foi introduzido na biomecânica ortopédica a partir da década de 1970 e, desde então, tem sido crescente o número de publicações de estudos de análise de carregamento em ossos, artroplastias e osteossínteses ${ }^{(4)}$.

Os objetivos deste trabalho são: a construção de um modelo computacional bidimensional representativo de um fêmur derivado de uma radiografia plana com aplicação do método dos elementos finitos e o estudo comparativo do desempenho biomecânico entre as hastes de aço e titânio, avaliando caminho e distribui- 
ção das tensões (Mises), tensões principais e deformações, considerando a simulação de um traço de fratura no modelo proposto, com o propósito de apontar o melhor método de síntese a adotar nas fraturas do fêmur da criança.

\section{MÉTODOS}

O método numérico computacional utilizado no presente estudo foi o dos elementos finitos (MEF), viabilizado por meio do aplicativo $A N S Y S^{\circledR}$, versão 10.0 , desenvolvido pela Swanson Analysis Inc., com auxílio de um computador Pentium IV de $2.800 \mathrm{MHz}$ (megahertz), com 256MB (megabyte) de memória e 40GB (gigabyte) de disco rígido, de propriedade do CESEC (Centro de Estudos de Engenharia Civil Inaldo Ayres Vieira), da Universidade Federal do Paraná (UFPR) $)^{(5)}$.

Adotou-se uma análise simplificada, bidimensional, resolvendo-se um problema de estado plano, utilizando um elemento finito isoparamétrico, do tipo triangular (Plane 2), quadrático de seis nós, com dois graus de liberdade em cada nó, que são translações nas direções X (horizontal) e Y (vertical), que não permite translações perpendiculares ao plano, conforme esquema 1, disponível na biblioteca da plataforma $A N S Y S^{\circledR(5)}$.

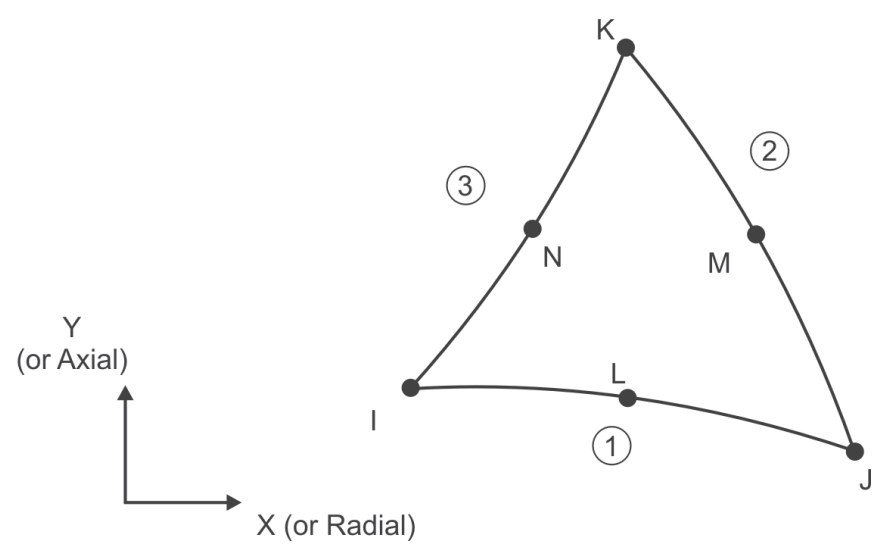

Esquema 1 - Elemento finito Plane 2

Fonte: ANSYS Release 10.0 Documentation. Houston, USA: Ansys Inc.; 2005(12).

Foram construídos três modelos a partir da radiografia plana panorâmica de ambos os fêmures na projeção ântero-posterior de um menino de oito anos que se encontrava no pós-operatório de seis meses de hastes flexíveis de titânio para o tratamento de fratura do fêmur direito, já consolidada, em que utilizamos o lado não lesado (esquerdo) para geração da imagem computacional (figura 1a). Os modelos foram gerados a partir de um modelo desenhado computacionalmente, utilizando-se o programa AutoCAD $2004^{\circledR}$.

$\mathrm{O}$ primeiro modelo simulou um fêmur em condições normais, íntegro, e foi obtido pela análise dos cortes em radiografia plana, com intervalo de $2 \mathrm{~cm}$ a partir do trocanter menor até a placa fisária distal (figura 1b). Nessa radiografia foi realizada a mensuração da espessura das corticais medial e lateral e também da medular em todos os cortes apresentados, totalizando 11 cortes, nos extremos proximal e distal, em nível epifisário, considerado o contorno visto na radiografia. Os modelos foram gerados a partir dessas informações pelo programa computacional AutoCAD ${ }^{\circledR}$ e foram exportados para a plataforma $A N S Y S^{\circledR}$, versão $10.0^{(5)}$.

Aplicado carregamento de $350 \mathrm{~N}$, o que corresponderia a uma criança de $35 \mathrm{~kg}$, orientado para o centro da epífise femoral, considerando apoio na região dos côndilos femorais (figura 1c) ${ }^{(6)}$.

Nos modelos para análise consideramos o mesmo desenho representativo do fêmur - porém, definindo um traço simulando uma fratura diafisária com espaçamento de $1 \mathrm{~mm}$ - e a simulação gráfica de hastes intramedulares de $4 \mathrm{~mm}$ de diâmetro de diferentes materiais: aço inoxidável e titânio, respectivamente, posicionadas de distal para proximal (técnica ascendente) (figura 1d). No modelo de fêmur íntegro, a malha de elementos finitos foi composta de 5.779 elementos triangulares (figura 1c). Nos modelos com as simulações das hastes, a malha foi composta de 9.378 elementos triangulares (figura 1e).

A espessura de cada uma das hastes utilizadas foi de $4 \mathrm{~mm}$, tanto para as de aço quanto de titânio, com o objetivo de preenchimento de $80 \%$ do canal medular, de acordo com a técnica preconizada ${ }^{(7)}$.

Adotou-se o critério proposto por Frost, em 1987, para a remodelação óssea baseado na magnitude da deformação interna ${ }^{(8)}$. Como as deformações nos ossos são tipicamente muito pequenas, é comum o uso do termo micro-strain ou $\mu$-strain $\left(10^{-6} \mathrm{~m} / \mathrm{m}\right)$. De acordo com essa teoria, intitulada de mecanostática, existem quatro regiões estabelecidas segundo valores de 


\section{$350 \mathrm{~N}$}
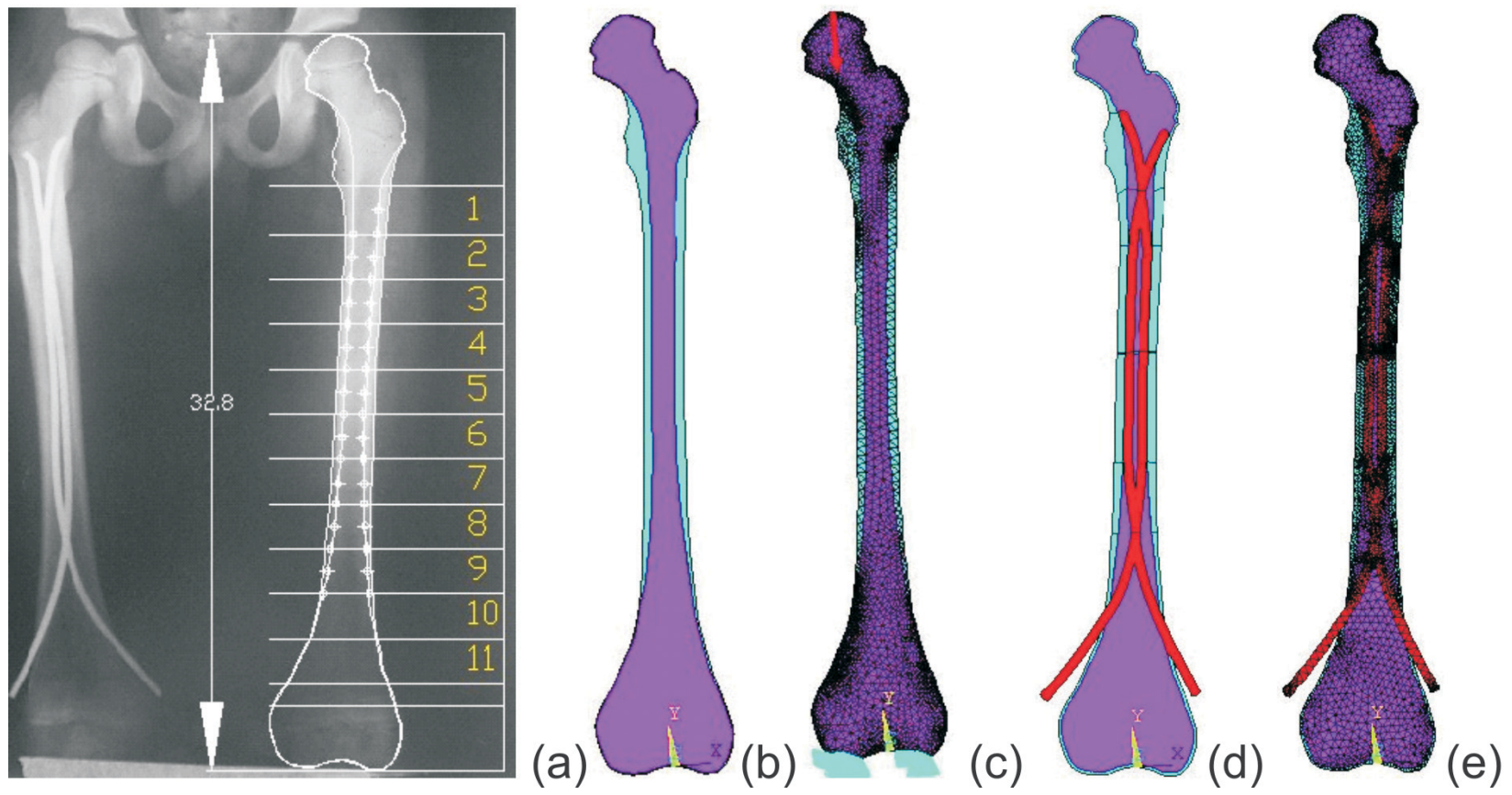

Figura 1 - (a) Radiografia do fêmur; (b) modelo do fêmur íntegro, indicando o osso trabecular osso cortical; (c) malha de elementos finitos do fêmur íntegro adotada, com indicação do carregamento e apoio nos côndilos; (d) modelo do fêmur com simulação do traço de fratura e posicionamento das hastes; (e) modelo completo com a malha de elementos finitos adotada.

$\mathrm{N}=$ Newton

deformação e relacionadas a um processo de "adaptação mecânica". As quatro "zonas" ou "janelas" incluem regiões associadas à falta de estímulo, à carga fisiológica, à de sobrecarga fisiológica e, finalmente, à de sobrecarga patológica ${ }^{(8)}$.

A atrofia devida à falta de estímulo de formação está entre 0 e $100 \mu$-strain, podendo ocorrer "janela de sobrecarga patológica" - perda da massa óssea - associada a valores acima de $\approx 4.000 \mu$-strain, enquanto as janelas fisiológicas - de equilíbrio - encontram-se entre $\approx 100$ e $4.000 \mu$-strain. Valores equivalentes a $\approx 1.500$ $4.000 \mu$-strain estão associados a ganho ou hipertrofia da massa óssea. Falência por fadiga começa a se instalar quando valores maiores de $\approx 4.000 \mu$-strain estão presentes; o máximo, $25.000 \mu$-strain, é atingido quando o tecido ósseo não resiste mais ao aumento de tensão e fratura ${ }^{(8)}$.

Hastes e osso foram modelados considerando isotropia e homogeneidade. Os valores do módulo de elas- ticidade (E) e do coeficiente de Poisson (v) usados na simulação do osso cortical e do osso trabecular foram obtidos na literatura ${ }^{(9)}$. Os valores do módulo de elasticidade (E) e do coeficiente de Poisson ( $v$ ) da liga TAN (Ti6Al7Nb) e do aço inoxidável foram fornecidos pelo fabricante, Synthes ${ }^{\circledR}$, e estão todos detalhados conforme a tabela 1.

Na simulação foi adotada uma força aplicada sobre a epífise femoral representando, de maneira simplificada, uma das cargas que atuam no fêmur de uma criança de aproximadamente oito anos, com peso corporal de $35 \mathrm{~kg}$, correspondente, segundo Taylor et al, a 4,3 vezes o peso $(350 \mathrm{~N})$ (figura $1 \mathrm{c})^{(6)}$.

Para análise comparativa do caminho e distribuição das tensões ( $\sigma_{\text {eq }}=$ Von Mises $)$ e tensões principais, consideramos o modelo do fêmur como um todo, com valores representados pelo gráfico de cores. Estudo comparativo das tensões foi realizado levando-se em conta os valores obtidos nos nós correspondentes. 
TABELA 1

Propriedades físicas dos materiais

\begin{tabular}{|c|c|c|c|c|}
\hline Material & $\begin{array}{l}\text { Módulo de } \\
\text { elasticidade } \\
\text { (E), MPa } \\
\text { (megapascal) }\end{array}$ & $\begin{array}{l}\text { Coeficiente } \\
\text { de Poisson } \\
\text { (v) }\end{array}$ & $\begin{array}{c}\text { Tensão de } \\
\text { resistência } \\
\text { última à } \\
\text { compressão } \\
\left(\sigma^{-}{ }_{u l t}\right), \mathrm{MPa} \\
(\text { megapascal) }\end{array}$ & $\begin{array}{c}\text { Tensão de } \\
\text { resistência } \\
\text { última à } \\
\text { tração } \\
\left(\sigma^{+}{ }^{+}\right), \mathrm{MPa} \\
\text { (megapascal) }\end{array}$ \\
\hline Aço inoxidável (F138) & 200.000 & 0,33 & 500 & 500 \\
\hline Titânio (Ti6Al7Nb) & 105.000 & 0,34 & 750 & 750 \\
\hline Osso cortical & 13.700 & 0,30 & 224 & 151 \\
\hline Osso trabecular & 7.930 & 0,30 & 80 & - \\
\hline Região da fratura & 1 & 0,49 & 1 & - \\
\hline
\end{tabular}

TABELA 2

Médias de valores obtidos, desvio-padrão e número de observações utilizadas para análise comparativa

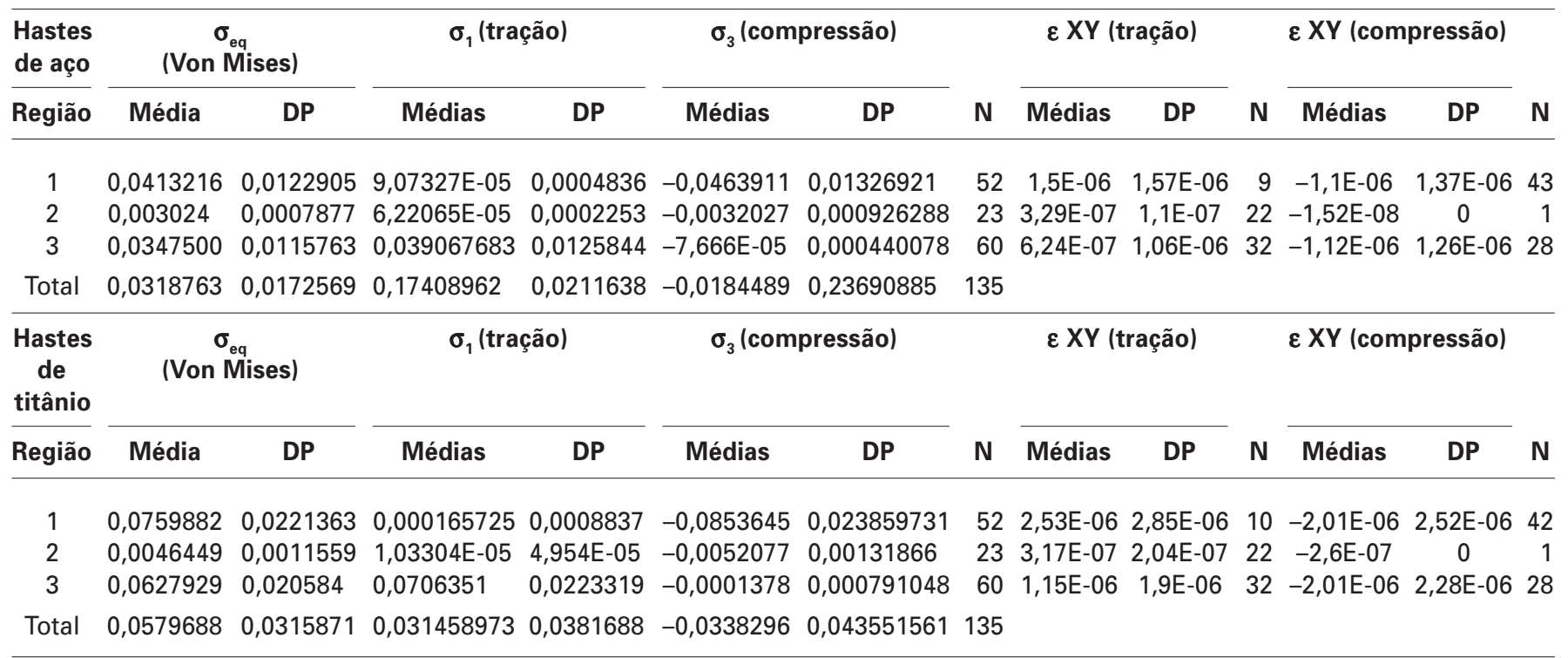

$\mathrm{DP}=$ desvio-padrão; $\sigma_{\text {eq }}=$ tensão equivalente $\left(\right.$ Von Mises); $\sigma_{1}=$ tensão principal de tração; $\sigma_{3}=$ tensão principal de compressão; $\varepsilon \mathrm{XY}=$ deformação no plano $\mathrm{XY} ; \mathrm{Ex}=10^{\times} ; \mathrm{N}=$ número de amostras.

Para análise dos resultados comparativos das deformações, consideramos apenas as regiões da simulação da fratura: 1 (medial), 2 (central) e 3 (lateral), correlacionando os valores de deformação obtidos com os critérios de "janelas de resposta do osso" segundo Frost $^{(8)}$.

\section{Metodologia estatística}

Foram calculadas medidas descritivas das variáveis em estudo para facilitar a construção das hipóteses estatísticas. Tabelas de médias, desvios-padrões e nú- mero de observações foram sumarizadas; a área de interesse foram as regiões 1, 2 e 3 no nível do foco de simulação de fratura (tabela 2). Foi aplicado o teste estatístico não paramétrico de Wilcoxon.

\section{RESULTADOS}

Os resultados do caminho e distribuição das tensões (em Pa) nos modelos de simulação do fêmur com hastes de aço e com hastes de titânio são apresentadas em uma escala de cores. Diferentes cores representam diferentes níveis de tensão no elemento analisado. 


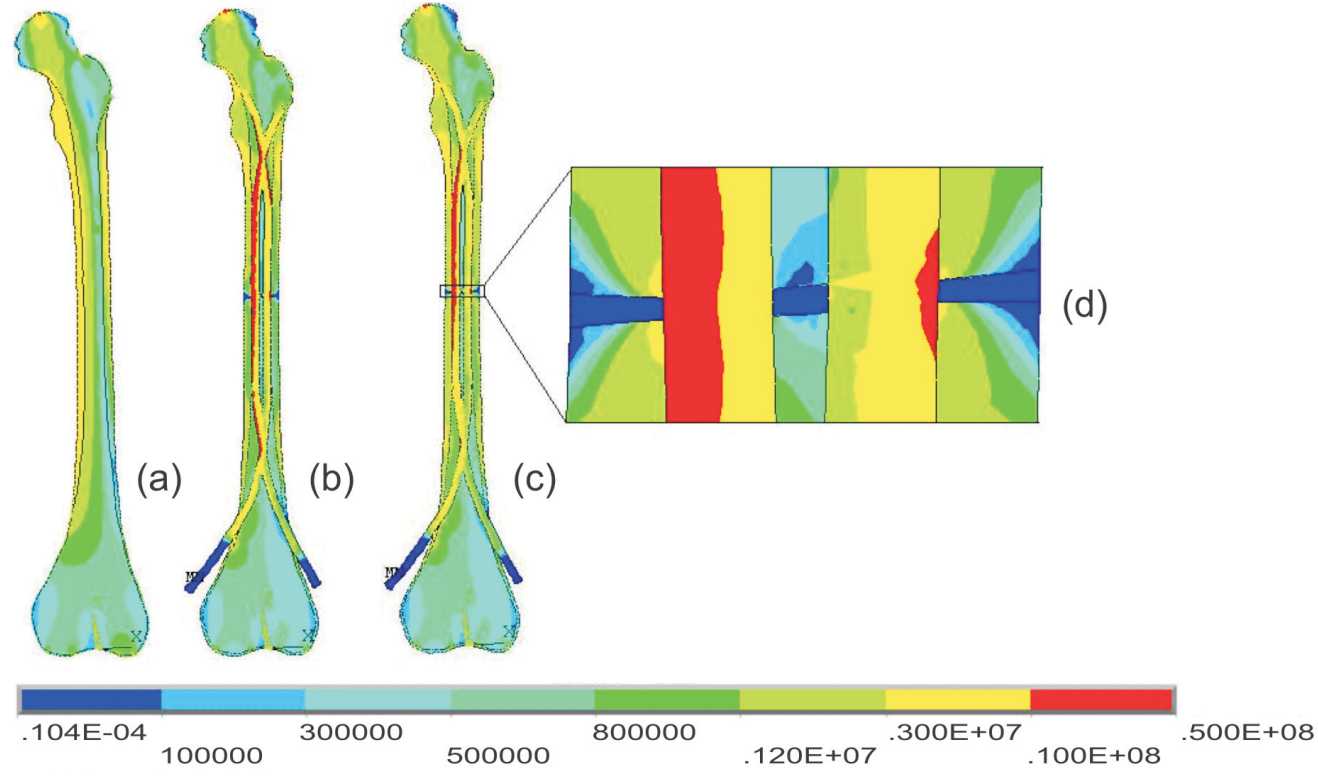

Figura 2 - Caminho e distribuição das tensões de Von Mises (Pa) nos modelos: (a) fêmur íntegro; (b) hastes de aço inoxidável; (c) hastes de titânio (Ti6Al7Nb); (d) detalhe da região da fratura; abaixo: gráfico em cores com valores em $\mathrm{Pa}=\mathrm{N} / \mathrm{m}^{2}$.

$\mathrm{Pa}=$ Pascal; $\mathrm{N}=$ Newton; $\mathrm{m}^{2}=$ metro quadrado

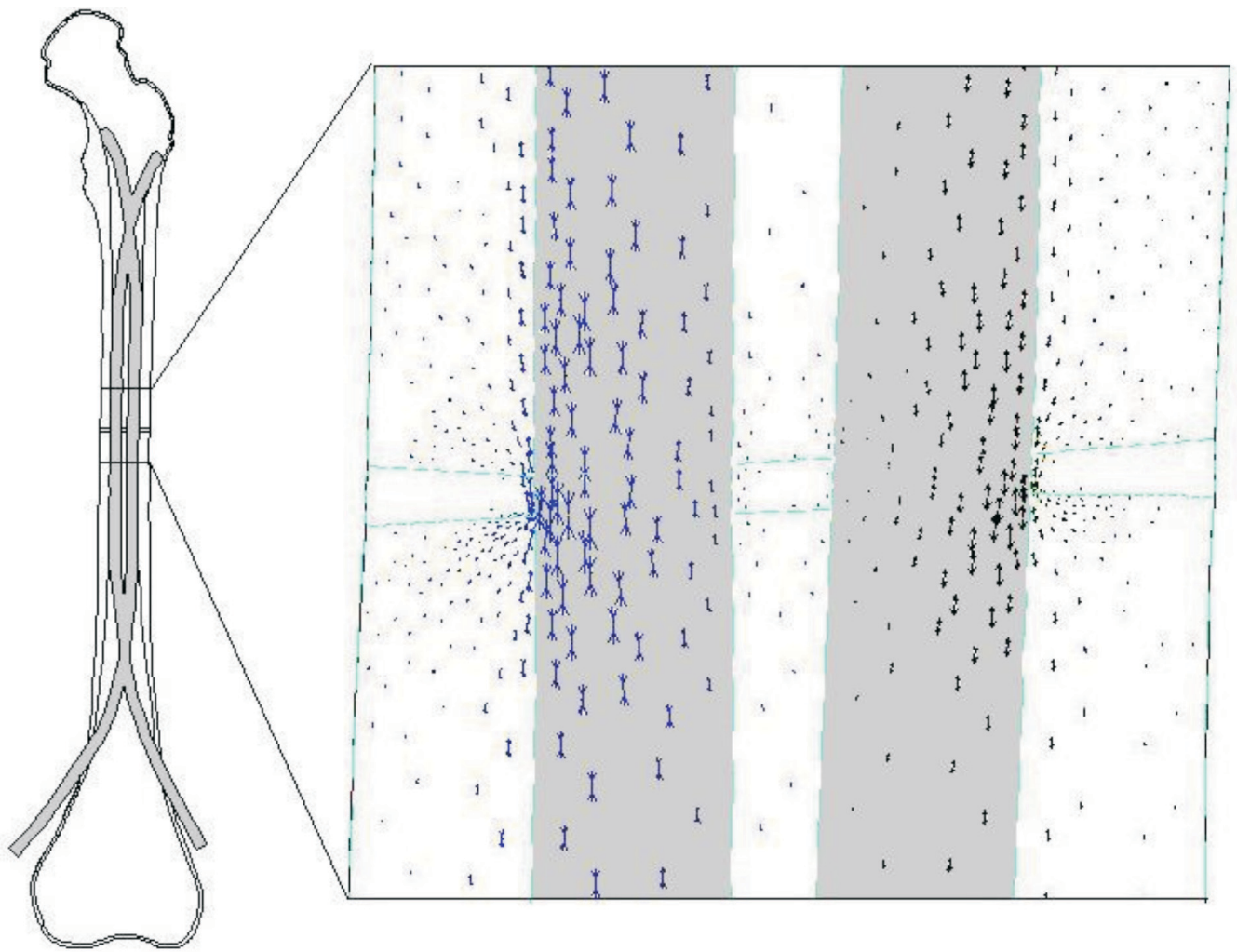

Figura 3 - Detalhe das tensões principais na região da fratura. As flechas em azul indicam tensões principais mínimas de compressão $\left(\sigma_{3}\right)$, enquanto as flechas em preto indicam tensões principais mínimas de tração $\left(\sigma_{1}\right)$. 


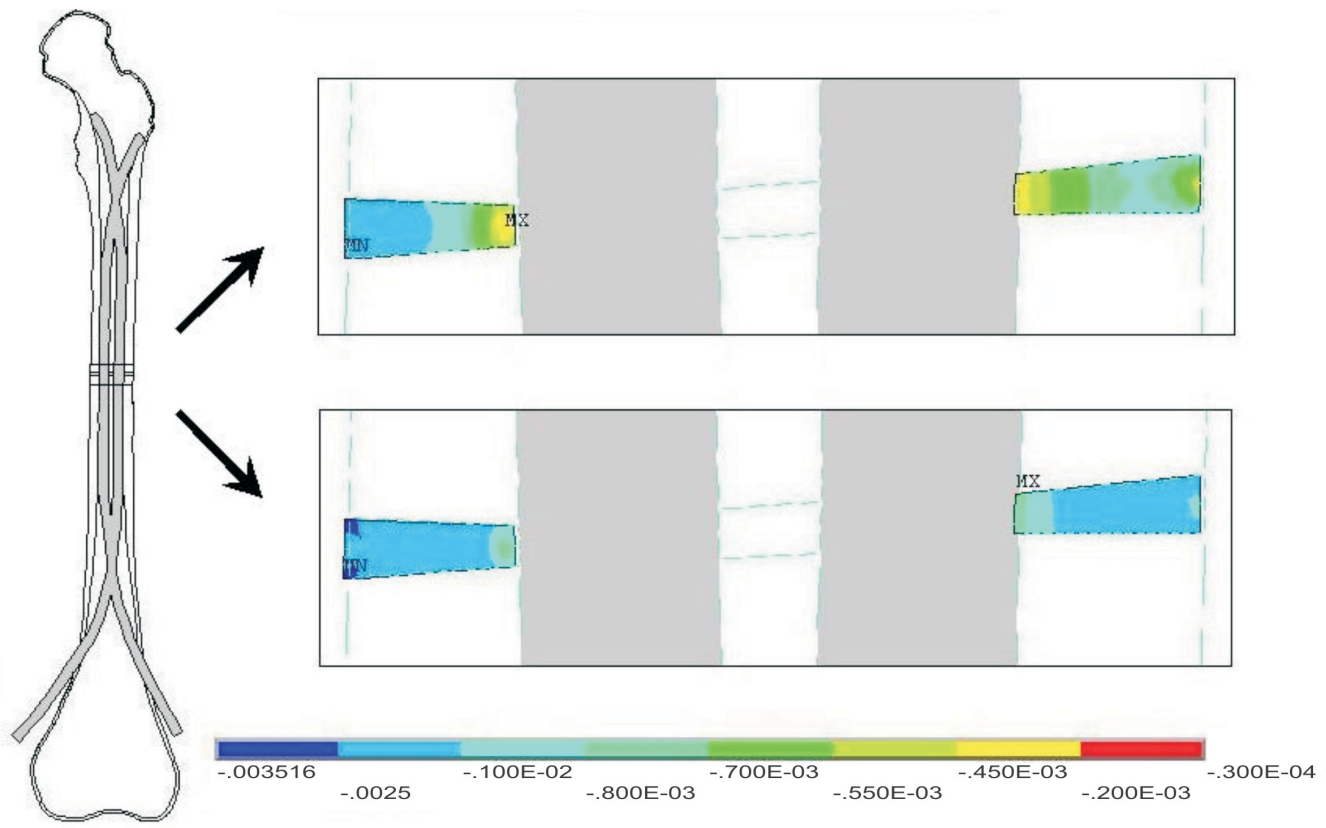

Figura 4 - Detalhe da distribuição da deformação principal de compressão $\varepsilon 3(\mathrm{~m} / \mathrm{m})$, na região da fratura para o modelo com: (a) haste de aço inoxidável e (b) haste de titânio.

Na interpretação do caminho e distribuição das tensões, observamos distribuição mais homogênea das tensões no modelo com hastes de titânio (figura 2).

$\mathrm{Na}$ interpretação da distribuição das tensões principais na região da fratura, em ambos os modelos de hastes, notamos que as tensões são absorvidas pelas hastes, variando apenas a magnitude das mesmas (figura 3).

Observamos distribuição mais adequada dos valores de deformação no modelo com hastes de titânio, pois encontramos os mesmos dentro da janela de equilíbrio e hipertrofia, enquanto isso não foi observado no modelo com hastes de aço. Valores expressos na figura 4 estão em negativo, pois traduzem deformações provocadas por compressão.

A tabela 3 expressa a análise estatística sumarizada nas variáveis de tensão (Von Mises), tensões principais e deformações, comparando o modelo de hastes de aço e titânio, considerando as regiões 1,2 e 3 .
TABELA 3

Análise estatística sumarizada

\begin{tabular}{|c|c|c|c|c|c|}
\hline \multirow[t]{2}{*}{ Região } & \multirow[t]{2}{*}{ Variável } & \multirow{2}{*}{$\frac{\text { Estatística }}{\mathrm{T}}$} & \multicolumn{2}{|c|}{$\mathbf{n}$} & \multirow[t]{2}{*}{ p-valor } \\
\hline & & & Aço & Titânio & \\
\hline \multirow{5}{*}{1} & $\sigma_{\mathrm{eq}}$ & 0 & 52 & 52 & $3,54868 E-10$ \\
\hline & $\sigma_{1}$ & 3 & 52 & 52 & * \\
\hline & $\sigma_{3}$ & 0 & 52 & 52 & $3,54868 E-10$ \\
\hline & $\varepsilon X Y($ tração) & 0 & 9 & 10 & 0,00768965 \\
\hline & $\varepsilon X Y$ (compressão) & 6 & 43 & 42 & $1,72478 \mathrm{E}-08$ \\
\hline \multirow{5}{*}{2} & $\sigma_{\text {eq }}$ & 0 & 23 & 23 & 2,70888E-05 \\
\hline & $\sigma_{1}$ & 3 & 23 & 23 & $*$ \\
\hline & $\sigma_{3}$ & 0 & 23 & 23 & $2,70888 \mathrm{E}-05$ \\
\hline & $\varepsilon \mathrm{XY}($ tração) & 105 & 22 & 22 & 0,485175133 \\
\hline & $\varepsilon X Y$ (compressão) & 105 & 1 & 1 & * \\
\hline \multirow{5}{*}{3} & $\sigma_{\text {eq }}$ & 0 & 60 & 60 & $1,65711 \mathrm{E}-11$ \\
\hline & $\sigma_{1}^{\text {eq }}$ & 0 & 60 & 60 & $1,65711 \mathrm{E}-11$ \\
\hline & $\sigma_{3}$ & 0 & 60 & 60 & $*$ \\
\hline & $\varepsilon X Y($ tração) & 0 & 32 & 32 & $7,99285 E-07$ \\
\hline & $\varepsilon X Y$ (compressão) & 0 & 28 & 28 & $3,8044 \mathrm{E}-06$ \\
\hline
\end{tabular}

$\sigma_{\text {eq }}=$ tensão (Von Mises)

$\sigma_{1}=$ tensão principal compressão

$\sigma_{3}=$ tensão principal tração

$\varepsilon X Y$ (tração) $=$ deformação no plano tração

$\varepsilon X Y($ compressão $)=$ deformação no plano compressão

* Considerado nível de significância de $5 \%(p<0,05)$, indica que não há diferença entre os materiais, muitos valores próximos de zero ( $\mathrm{p}$-valor muito alto) 


\section{DISCUSSÃO}

A estabilidade das hastes flexíveis de titânio parece ser superior à das hastes de aço, segundo os resultados biomecânicos de Mahar et al, em 2004, em modelo de osso artificial $^{(3)}$.

As estruturas ósseas estão normalmente expostas a cargas extremamente complexas e a sua influência acumulativa governa a biologia dos tecidos e determina sua histomorfologia ${ }^{(10)}$. Uma das propriedades mecânicas mais relevantes na análise de estruturas biomecânicas é a rigidez do material. O módulo de elasticidade ou de Young (E) - aplicada a materiais elásticos - tem a função de descrever a rigidez de um material. Quanto maior o seu valor, mais rígido é o material.

Nas pesquisas e projetos dentro da Ortopedia encontra-se, de maneira crescente, a utilização do método dos elementos finitos como instrumento para predizer os efeitos das tensões nos tecidos ósseos e adjacentes quando submetidos a carregamento. A forma e as propriedades físicas dos materiais são construídas por computação e as interações físicas dos vários componentes do modelo são calculadas em termos de tensões e deformações que ocorrem nos tecidos ${ }^{(11)}$.

O MEF considera as estruturas como sendo uma reunião de pequenas partículas de quantidade finita, denominadas de elementos finitos, conectados a um número finito de pontos, chamados de nós ou pontos nodais ${ }^{(12)}$. Por meio do MEF, pode-se avaliar a distribuição das tensões em uma estrutura, observando a deformação no elemento ou visualizando e interpretando as imagens, através de um gráfico de $\operatorname{cores}^{(13)}$.

Huiskes et al revisaram a literatura e definiram o método dos elementos finitos como uma avançada técnica computadorizada de análise de cargas sobre estruturas, derivado da engenharia mecânica ${ }^{(4)}$. As tensões e deformações podem ser decompostas em duas parcelas: parcela hidrostática e parcela desviadora ou octaédrica $^{(10)}$. Em um corpo composto por um material elástico e isotrópico, as tensões hidrostáticas causam apenas mudança de volume, enquanto as tensões desviadoras ou octaédricas provocam mudança de forma ou distorção.

Segundo Rowling, a fórmula de Von Mises é o critério isotrópico mais adequado para predizer o escoa- mento de materiais dúcteis como os metais ${ }^{(14)}$. Apesar de ser o critério mais usado para avaliar materiais dúcteis, que apresentam o mesmo comportamento na tração e compressão, o critério de Von Mises tem sido utilizado com freqüência para avaliar o material ósseo sob carga. Nesse caso, a falha do material ocorre quando a tensão equivalente é igualada à tensão última de resistência ${ }^{(9)}$.

A cura de uma fratura é tópico importante de pesquisa em biomecânica e seus estudos iniciaram-se, segundo Huiskes ${ }^{(15)}$, com os trabalhos de Roux ${ }^{(16)}$ e Wolff ${ }^{(17)}$. A capacidade adaptativa do tecido ósseo foi descrita por Wolff, quem considerou o osso com uma estrutura capaz de adaptar-se às condições de carregamento externo ${ }^{(17)}$. Durante os últimos anos, muitas teorias e modelos de simulação têm sido propostos para desenvolver uma visão compreensiva dos mecanismos que controlam a morfogênese óssea, tanto do ponto de vista ontogenético como filogenético ${ }^{(18)}$.

Quando o tecido ósseo é exposto a solicitações mecânicas, as tensões podem regular uma mudança no tipo do tecido, ou seja, a célula mesenquimal poderá se modificar em diferentes tipos de células, formando um tipo de tecido ou outro (diferenciação celular) ${ }^{(19)}$. Charles-Harris et al assumem como válidas essas teorias e as utilizam na busca do conhecimento das tensões e deformações em um calo de fratura ou ao redor de um implante, bem como sua influência na diferenciação dos tecidos que podem conduzir a compreensão melhor dos processos mecanicamente controlados de diferenciação dos tecidos, possibilitando, desse modo, ajudar a melhorar não só o tratamento de fraturas, como também os projetos de implantes ${ }^{(20)}$. Nas fraturas, o desenvolvimento do processo curativo está relacionado à estabilidade dos fragmentos da fratura (micromobilidade) que, por sua vez, influencia as condições mecânicas locais.

Claes et al relataram que o conhecimento das tensões e deformações nas células presentes no calo ósseo e suas influências na diferenciação celular permitem melhor entendimento do processo e pode auxiliar na melhora do tratamento das fraturas. Entretanto, não é possível determinar tensões e deformações nas células do calo ósseo in vivo. Apresentaram estudo inter- 
disciplinar comparando os dados de uma experiência animal com os resultados de uma análise computacional utilizando o método dos elementos finitos, para avaliação da influência do tamanho da abertura da fratura e da deformação interfragmentária no processo de cura de fraturas e formularam uma teoria mecanoregulatória ${ }^{(21)}$. Essa teoria é muito semelhante à desenvolvida por Carter et $a l^{(10)}$.

Taylor et al analisaram a distribuição das tensões em um modelo do fêmur derivado de um cadáver adulto humano utilizando o método dos elementos finitos. Observaram que, nesse modelo, o fêmur é submetido principalmente às tensões de compressão ${ }^{(6)}$.

Foram utilizados no modelo proposto: 1) o elemento triangular de seis nós, isoparamétrico, quadrático, com dois graus de liberdade; 2) triangular, por adaptar-se de maneira mais adequada à geometria irregular do modelo; 3 ) de seis nós, pois possibilita aferição das tensões com relativa precisão (máximo de nós permitido no programa computacional); 4) isoparamétrico, por possuir o mesmo número de nós no seu interior, para cálculo interno do programa; 5) quadrático, porque o programa oferece equações que possibilitam a melhor adequação à forma do objeto para análise; 6) dois graus de liberdade, por permitir que os nós se desloquem apenas no plano frontal.

O modelo adotado considerou a simulação da força axial, não levando em consideração as forças musculares, tampouco a mobilidade articular; esses fatores predispõem a análise mais complexa com maior número de variáveis, dificultando a simulação computacional, sem acrescentar considerações importantes para o estudo. $\mathrm{O}$ uso de um modelo bidimensional permitiu o entendimento da resposta mecânica e, em especial, a comparação do comportamento biomecânico da haste de titânio com o da haste de aço inoxidável, nos modelos propostos.

A figura 2a mostra as tensões equivalentes ou de Von Mises no modelo de fêmur íntegro, composto apenas por material granular (osso). As figuras $2 \mathrm{~b}$ e $2 \mathrm{c}$ mostram as tensões equivalentes ou de Von Mises nos modelos que contêm hastes de aço inoxidável e de liga de titânio TAN (Ti6Al7Nb), respectivamente. Do ponto de vista constitutivo, os modelos com hastes se di- ferenciam do modelo de fêmur íntegro, pois possuem, além de material granular, hastes de material dúctil. Apresentam, portanto, número de nós em maior quantidade.

Percebe-se que no modelo de fêmur íntegro, tensões maiores estão presentes no osso cortical (regiões em amarelo), enquanto que nos modelos de fêmur com simulação do traço de fratura e hastes posicionadas, as forças de compressão passam a ser induzidas pelas hastes que, com sua maior rigidez em comparação com a óssea, servem de "tutoras" das cargas, "protegendo" o osso.

O modelo com a haste de aço inoxidável apresentou maiores tensões equivalentes do que o modelo com a haste de titânio, ou seja, o material mais rígido (aço inoxidável) induz maiores tensões que o material menos rígido. Observa-se que no modelo com osso intacto as tensões na diáfise ficam restritas ao osso cortical no nível de 10 x 106Pa (pascal) ou $10 \mathrm{MPa}$ (megapascal), enquanto no osso trabecular ficam restritas ao nível de 3 x 106Pa ou 3MPa, valores que podem ser considerados baixos, comparado-os com os limites de ruptura por compressão dos ossos cortical e trabecular de 224MPa e 80MPa, respectivamente, encontrados por Rodrigues $^{(22)}$.

Nos modelos com as hastes, as tensões na diáfise nos ossos cortical e trabecular ficam bem mais reduzidas, não excedendo 3MPa no osso cortical, chegando a assumir valores nulos na região da fratura. Já na topografia das hastes, as tensões equivalentes ou de Von Mises não excedem 50MPa.

Na região da fratura, a tensão é absorvida pelas hastes, porém, o fato de a haste de titânio ser menos rígida do que a haste de aço inoxidável induzirá micromobilidade desejável, que contribuirá para a formação óssea.

Isso, de certa maneira, pode explicar a maior formação de calo ósseo, radiograficamente observada quando são utilizadas hastes intramedulares flexíveis de titânio $^{(2)}$. Entretanto, em situações de instabilidade exagerada, a mobilidade induzida pelas hastes flexíveis pode predispor ao retarde de consolidação e/ou pseudartrose. Por outro lado, rigidez excessiva do implante pode, da mesma maneira, levar a transtornos da consolidação. 
Analisado globalmente, o modelo com hastes de titânio produziu resultados biomecânicos desejáveis, pois a distribuição das tensões deu-se de forma homogênea. A concentração maior das tensões nas hastes de aço é observada pela concentração da cor vermelha distribuída em uma extensão maior nas mesmas, indicando "absorção" superior das tensões pelas hastes de aço. Além de, nesse modelo, com referência à teoria mecanostática de Frost, ter proporcionado melhor resposta quanto à formação óssea na região de simulação da fratura ${ }^{(8)}$.

\section{CONCLUSÕES}

1) O modelo proposto atinge os objetivos de comparar as tensões e deformações entre as simulações das hastes de titânio e aço, apresentando resultados compatíveis com a fisiologia óssea, os quais geram análises quantitativas e qualitativas que permitem comparar o efeito da introdução de hastes intramedulares de diferentes materiais.

2) Analisando o caminho e distribuição das tensões no modelo (Von Mises e tensões principais), considerando o fêmur total, observa-se qualitativamente melhor comportamento biomecânico no modelo com hastes de titânio; todavia, na análise quantitativa, restrita às regiões 1,2 e 3 , os valores são estatisticamente semelhantes.

3) No estudo das deformações, observa-se comportamento biomecânico mais homogêneo no modelo com hastes de titânio, pois as deformações verificadas nas regiões 1, 2 e 3 apresentam dentro da janela fisiológica: hipertrofia-equilíbrio-equilíbrio. No modelo de hastes de aço observam-se: equilíbrio-equilíbrio-atrofia.

\section{REFERÊNCIAS}

1. Ligier JN, Metaizeau JP, Prévot J, Lascombes P. Elastic estable intramedullary nailing of femoral shaft fractures in children. J Bone Joint Surg Br. 1988;70(1):74-7.

2. Flynn JM, Luedtke L, Ganley TJ, Pill SG. Titanium elastic nails for pediatric femur fractures: lessons from the learning curve. Am J Orthop. 2002;31(2):71-4.

3. Mahar AT, Lee SS, Lalonde FD, Impelluso T, Newton PO. Biomechanical comparison of stainless steel and titanium nails for fixation of simulated femoral fractures. J Pediatr Orthop. 2004;24(6):638-41.
4. Huiskes R, Chao EY. A survey of finite element analysis in orthopedic biomechanics: the first decade. J Biomech. 1983; 16(6):385-409.

5. ANSYS Release 10.0 Documentation. Houston, USA: Ansys Inc.; 2005.

6. Taylor ME, Tanner KE, Freeman MA, Yettram AL. Stress and strain distribution within the intact femur: compression or bending? Med Eng Phys. 1996;18(2):122-31. Comment in: Med Eng Phys. 1997;19(1):97, 99-100.

7. Flynn JM, Hresko T, Reynolds RA, Blasier RD, Davidson R, Kasser J. Titanium elastic nails for pediatric femur fractures: a multicenter study of early results with analysis of complications. J Pediatr Orthop. 2001;21(1):4-8.

8. Frost HM. Bone "mass" and the "mechanostat": a proposal. Anat Rec. 1987;219(1):1-9.

9. Doblaré M, García JM. On the modelling bone tissue fracture and healing of the bone tissue. Acta Cient Venez. 2003;54(1): 58-75. Review.

10. Carter DR, Beaupré GS, Giori NJ, Helms JA. Mechanobiology of skeletal regeneration. Clin Orthop Relat Res. 1998;(355 Suppl):S41-55.

11. García JM, Doblaré M, Cegoñino J. Bone remodelling simulation: a tool for implant design. Comput Mater Sci. 2002; 25(1-2):100-14.

12. Zienkiewicz OC. The finite element method. 3rd expanded and rev. ed. London; New York: McGraw-Hill; c1977.

13. Bathe KJ. Finite element procedures. Englewood Cliffs, N.J.: Prentice Hall; c1996.

14. Rowling NE. Mechanical behavior of materials: engineering methods for deformation, fracture, and fatigue. Upper Saddle River, NJ: Prentice Hall; 1998.

15. Huiskes R. If bone is the answer, then what is the question? $\mathrm{J}$ Anat. 2000;197(Pt 2):145-56.

16. Roux W. Der kampf der teile im organismus. Leipzig: Engelmann; 1881.

17. Wolff J. Das gesetz der transformation der knochen. Berlin: Hirchwild; 1892. [Traduzido por Maquet P, Furlong R. The law of bone remodeling. Berlin: Springer; 1986].

18. Lacroix D, Prendergast PJ. A mechano-regulation model for tissue differentiation during fracture healing: analysis of gap size and loading. J Biomech. 2002;35(9):1163-71.

19. Isaksson $H$, van Donkelaar $C C$, Huiskes $R$, Ito $K$. Corroboration of mechanoregulatory algorithms for tissue differentiation during fracture healing: Comparison with in vivo results. J Orthop Res. 2006;24(5):898-907.

20. Charles-Harris M, Lacroix D, Proubasta I, Planell JA. Intramedullary nails vs osteosynthesis plates for femoral fracture stabilization: A finite element analysis. J Appl Biomater Biomech. 2005;3:157-67.

21. Claes LE, Heigele CA. Magnitudes of local stress and strain along bony surfaces predict the course and type of fracture healing. J Biomech. 1999;32(3):255-66.

22. Rodrigues MES. Análise do risco de fratura óssea por ultrasonometria e ensaio mecânico de compressão [Dissertação]. São Carlos: Universidade de São Carlos; 2003. 